\title{
Diffusion of Good Government: Social Sector Reforms in Brazil
}

\author{
by Denilson Bandeira Coêlho \\ Political Science Institute, University of Brasília (UNB), Brazil
}

(SUGIYAMA, Natasha Borges. The Diffusion of Good Government: Social Sector Reforms in Brazil. Notre Dame: University of Notre Dame Press, 2012)

$\mathrm{T}$ he book Diffusion of Good Government: Social Sector Reforms in Brazil by Natasha Sugiyama is one of the most important recent contributions to a literature dedicated to confronting the policy choices made by States who face the persistence of poverty and social inequality in Latin America. With a theoretical and methodological support that mixes traditional and sophisticated approaches to the study of the formation of new agendas, the author presents an original analytical vision of the factors which orient the mechanisms behind the formulation of public policies in countries with a complex institutional arrangement, such as Brazil, a highly decentralized federation with specific attributes as to the definition of a social protection network. The author's central interest is to investigate why and how these social reforms originate and are diffused among sharply distinct governmental units in terms of their administrative capacity, fiscal contribution, socioeconomic development, and political and cultural history. In order to develop her analysis the author selects two programs implemented in the country from the mid1990s, which currently represent two of the main national policies in health and education: Family Health Program and School Grant Program ${ }^{1}$ (Programa Saúde da Família and Programa Bolsa Escola). Therefore, based on the municipal adherence to both programs, the object of the research is to investigate why ideas which represent social solutions arise and are adopted by a set of governments in time. According to theorists such as Heclo (1974) and Kingdon (2011), these ideas are proposals marked by new forms and

1 The School Grant Program was incorporated to the Family Grant Program (Programa Bolsa Família) as of 2003. 
resources potentially applicable in a conservative system dominated by traditional rules and models for public policies. In a rereading that approaches classical views such as the one by Cohen, March and Olsen (1972) concerning the institutional changes in anarchically organized systems, Sugiyama then becomes interested in explaining the factors that motivate similar political behavior within contexts of diffuse social reforms. To this goal the author defines a multi-method research framework that brings together qualitative and quantitative approaches with an extensive fieldwork, comparing major cities and applying the Event History Analysis (survival analysis) statistical model with an interest in analyzing the factors that explain the different time periods for adopting the programs among government leaders.

According to the author, the advantage in applying survival analysis is that the model allows us to annually observe the interdependence among jurisdictions, thus allowing for a more thorough analysis of the internal and external determinants in diffusion processes. In diffusion studies that seek to investigate the political behavior of actors in political decision-making, the determinants employed in the analysis are based in three explanations: political incentives, ideology and the role of social networks.

Starting from this approach, the author skillfully develops and adapts each one of these theoretical perspectives in order to test how electoral motivations, ideological formation or participation in social networks influence or motivate political actors to emulate innovative social programs. By treating these schools of thought as rival explanations, the author points out, in reference to Walker (1969), that more electorally competitive jurisdictions probably replicate more policies since the actors act rationally in the sense of attending the voters' social demands. When referring to Mullins (1972), the author signals that certain principles or worldviews guide ideological preferences and, to this sense, political actors in an ideological spectrum closest to the left are eventually more inclined to adopt innovative institutional designs. Following in the footsteps of Balla (2001) and other scholars, Sugiyama examines if the participation of actors in social networks - professional associations, for example - would increase the odds of diffusing political practices thanks to the information exchange or socialization of norms. Still in the first chapter Sugiyama makes it clear to the reader that the State of the Art of her research was built on arbitrary selections in order to enable and to operationalize the research's theoretical-conceptual and methodological framework. Therefore, the research focuses on municipalities with a population higher than one hundred thousand inhabitants, making for a total universe of 224 cases, according to the IBGE data from the year 2000.

In the second chapter the author dedicates herself to the historical debate that illustrates the utility of diffusion theories in political science as well as developing an original argument so as to present the framework of her investigation. As described, the concept of 
diffusion is an issue in dispute by the specialized literature within this field of analysis. In a simple and objective manner, Sugiyama informs the reader that, in spite of a hodgepodge of denominations such as "contagion", "waves" and "transference" used to describe the phenomenon of replication of political events, such positions in fact attempt to explain the issue of diffusion of an innovative political solution. The difference is that the contagion effect is applied to cases in which replication occurs in an extremely fast manner due to advantageous attributes of the policy at stake. The waves are episodes that occur after long periods of stability in the political system and which configure themselves as almost inevitable events, such as re-democratization processes, where the regime transition of a country decisively influences the transition of another country.

The transference of policies differs from the previous ones because, hypothetically, it generates some type of learning among the actors and consolidates effective institutional actions. But what brings these perspectives together to the point that the author opts for simplifying the concept of diffusion is precisely her reluctance in assuming a priori the rationale of the decision for the adoption of new policies. Instead, the employed premise is that the adoption of new policies is an autonomous decision that takes place over time as a result of one or several factors in an interconnection amongst potential adopters. By restraining from the traditional impulse of defining a pure theoretical framework and delineating instead a multidimensional notion to examine the diffusion of Family Health Program and the School Grant Program, the author contributes to the theoretical debate by arguing that the diffusion process is a dynamic process, which takes place over a time, and where the probability of governmental administrations adopting the programs is directly correlated to previous decisions by different administrations. In synthesis, by illustrating the complexity in explaining political behavior in social reforms, the author alerts that, even in an indirect manner, the diffusion of a program cannot be mistaken for an automatic copying process or for a typical decentralization process. This is because the adoption of programs such as the Family Health Program and the School Grant Program generate administrative and budget costs, as well as commitments for accomplishing certain social goals, both being elements that impact governmental administrations distinctly. Within this perspective, even though she does not substantially advance the discussion, Sugiyama makes it clears that the results which mark the dissemination of a policy model depends on how the adopters - in this case, the local governments - were influenced by the political system. That is, the analysis lies not on the positive or negative aspects of innovation, but it does leave some clues to be further investigated in future works concerning the protagonism of local actors, which since the Federal Constitution of 1988 were given legal autonomy to create their own policies, and thus turned the municipalities into policy laboratories. 
The subsequent chapters are dedicated to an empirical analysis with the objective of providing causal explanations for the adoption of the Family Health Program and the School Grant Program. In the third chapter the conceptual-theoretical framework is structured in the survival analysis statistical model in order to test the influence of electoral competition, ideological convictions, social network connectivity, and other independent variables in the emulation of health of education programs. In the study, each logistic model measured the risk of the "adoption" to happen by means of annual observations. As for the School Grant Program the observations were spread out between 1995 and 2003 for the Family Health Program from 1994 until 2003. The results of the statistical regressions show that factors such as ideology and social networks decisively influenced the diffusion of both programs. As underlined by the author, in spite of the striking differences between the School Grant and the Family Health Program, and their different replication rates among the municipalities, both policies were disseminated by similar determinants. The analysis for both the School Grant Program and the Family Health Program reveals that the effect of electoral competition was null, which means that the adoption of such programs was not motivated by electoral disputes in either case. Such result contradicts a long tradition in the rational choice literature and is clearly closer to a sociological approach, since the study highlights that the actors' motivation is influenced by factors of a social nature and not by individual choices interested in political reelection. Other variables that could potentially influence the diffusion of policies were tested as being the effects of geographic neighboring and other control variables that represent internal needs, such as the municipal Human Development Index (HDI-M), which aggregates several indicators for well-being, population size, and federal funding for the specific case of Family Health Program. The results interestingly reveal that high levels of HDI-M and the larger size of a city were only significant for the adoption of the School Grant Program, and that informal networks such as geographical proximity and federal spending mattered for the diffusion of the Family Health Program. By questioning her own research findings in the concluding section of this chapter, Sugiyama casts a relevant research question and wonders if in fact the proxies used to measure the main model variable reflect the real political dynamics in the emulation of the programs. This is the key for accommodating a classical methodological debate within the political sciences, which, to some extent, sometimes divide these approaches to the point of not recognizing pure statistical findings. Therefore, with the clear intention of placing forward a complementary methodological mix, the author seeks to add, by means of a process-tracing method, the qualitative elements that more appropriately clarify interest issues, such as if mayors considered adopting programs in order to increase their reelection prospects, the importance of social networks for the municipal political life or even if ideology affects a local level decision making process. 
Therefore, chapters 4 and 5 are constructed so as to better illustrate the results from the applied research and describe in detail the political and institutional context that marked the health and education reforms during the 1990s. In these sections of the book the author underlines how reformist objectives within each sector were built to allow for the adhesion of local governmental administrations. However, at the same time, Sugiyama reminds us that the proposals for reforming the social field present several veto points due to the fact that their objectives seek to increase equity, and thus challenge the actors' status quo and limit the political patronage of typically clientelistic arrangements. Despite similar challenges for their attainments, both programs have distinct fundamental bases concerning their implementation viability. The argument is that the School Grant Program emerged as a simple idea to partially solve education issues that directly afflicted families, and thus perpetuate intergenerational poverty in the country. The solution found in order to increase school attendance and, consequently, the children's school performance and progression, besides allowing for those responsible for the children to work for longer periods of time, was to expand the students' time period in the educational system and to set up a monetary transfer to poor families. As for the Family Health Program, the argument is that the program was created from a complex solution since it took place amidst the health reform where controversial issues were being debated, such as the paradigm change for medical treatment, the municipalization of services and the rules for policy funding by means of regulation. Political reforms of such nature counteract in a set of institutions and actors and generate high reorganization costs for entities that form and represent professionals in sectors such as universities and labor unions. But one of the merits of this work is precisely to unveil the black box of the formulation process behind the analyzed programs so as to comprehend the motivations of local actors who, even when faced with several barriers, decided to emulate the Family Health Program and the School Grant Program. By analyzing the events in the state capital cities of São Paulo, Brasília, Belo Horizonte and Salvador during the period of three majoritarian elections ${ }^{2}$, the author concludes that for both cases the electoral competition does not explain the decisions to emulate or to reverse the adoption of either program. On the contrary, the interviews illustrate that ideology, as well as the affiliation to social networks, prompted mayors to diffuse such experiences. On the one hand, highly competitive political environments such as in the city of São Paulo would only come to adopt the Family Health Program and the School Grant Program during the Workers Party administration (Partido dos Trabalhadores PT), the partisan institution more closely tied to social networks and to a reformist ideology. On the other hand, the PT did not adopt the School Grant Program in the city of Belo

The analyzed period for Brasília encompasses the administrations between 1994 and 2002 and for the other three capitals the administrations between 1993 and 2004. 
Horizonte, and in Brasilia there were reversal situations. In Sugiyama's view the results show that, in spite of the expected logic of an explanation centered on political incentives, the decisions were mostly guided by ideological conditions or social beliefs, allowing her to conclude that the commitments for social justice and the connections between actors were the most relevant elements.

In the book's final chapter, one of the emblematic results informed by the author is that when the decision to emulate is mostly motivated by ideology there is a higher probability of a reversal decision. This happens since the adoption is then strongly centered in the policy maker's individual actions. In situations where the program is adopted due to norms in professional networks, replication happens more swiftly and the decision becomes stable over time, considering that the adoption is motivated by an institutionalized pattern consolidated during the course of governmental administrations. In summary, by focusing on the reformist agenda of local governments the hereby analyzed work inaugurates and consolidates a research agenda that places the Brazilian case as the most promising study laboratory for diffusion of public policies. Furthermore, she alerts to the need of reinterpretations of historical phenomena that have been studied under the light of a normative approach or by simplistic models that have privileged the role of the central government and dismissed the internal municipal determinants or the actors' political behavior. Lastly, the book holds great scientific merit for hereon instructing comparative researchers concerned with explaining similar phenomena in other countries.

\section{References}

BALLA, Steven J. (2001), Interstate professional associations and the diffusion of policy innovations. American Politics Research, vol.29, n³, pp. 221-245.

COHEN, Michael D.; MARCH, James G. and JOHAN, Olsen P. (1972), A Garbage Can Model of Organizational Choice. Administrative Science Quarterly, vol. 17, $\mathrm{n}^{\circ}$ 1, pp. 1-25.

HECLO, Hugh (1974), Modern Social Politics in Britain and Sweden: From Relief to Income Maintenance. New Haven, Yale University Press.

KINGDON, John W. (2011), Agendas, Alternatives and Public Policies. Boston: Longman.

MULLINS, Willard (1972), On the concept of ideology in political science. American Political Science Review, vol. 66, n²2, pp. 498-510.

WALKER, Jack (1969), The Diffusion of Innovations Among the American States. American Political Science Review, vol. 63, n³, pp. 880-899. 